\title{
The organization of information retrieved from situation models
}

\author{
GABRIEL A. RADVANSKY \\ University of Notre Dame, Notre Dame, Indiana
}

\begin{abstract}
The organization of information when it is retrieved from situation models was explored using recognition and recall tests. A fan effect paradigm was used to assess organization in recognition and a clustering measure was used in recall. People memorized either object-location facts (e.g., "The pay phone is in the city hall") or person/small location facts (e.g., "The banker is on the witness stand"). For object-location facts, a location-based organization was observed in both recall and recognition. However, for person/small location facts, a location-based organization was observed for recall, and a personbased organization was observed for recognition. Thus, the observed organization was flexible depending on the retrieval task.
\end{abstract}

This paper addresses the organization of information retrieved from situation models (Johnson-Laird, 1983; van Dijk \& Kintsch, 1983; Zwaan \& Radvansky, 1998). Situation models are representations of situations as they would exist in a real or possible world. In reading, situation models represent the situation described by a text, rather than the text itself (Glenberg, Meyer, \& Lindem, 1987). As such, they include information derived from the text as well as inferences generated from world knowledge. A situation model contains a set of tokens denoting entities that stand in relation to one another in a spatialtemporal framework (Radvansky \& Zacks, 1997; Zwaan \& Radvansky, 1998). Thus, a situation model serves as a mental simulation of a situation. The issue addressed here was whether a consistent organization would be observed in memory for information stored in situation models.

Compatible with the idea that situation models have a stable influence on memory performance, there is some evidence of consistent organizational patterns across a number of tasks. For example, research on the influence of spatial relations in situation models has found effects of distance using both memory probe (Glenberg et al., 1987; Morrow, Greenspan, \& Bower, 1987) and reading time measures (Glenberg et al., 1987; Rinck \& Bower, 1995). Also, effects of causal relations have been found

Portions of the research reported here were presented at the 1992 meeting of the Psychonomic Society in St. Louis. This research was supported in part by National Institute on Aging Grant AGO 4306 awarded to Lynn Hasher and Rose Zacks, and in part by NIMH National Research Service Award MH14257, while G.A.R. was a postdoctoral trainee in the Quantitative Methods Program of the Department of Psychology, University of Illinois at Urbana-Champaign. I would like to thank Laura Carlson-Radvansky, Tom Carr, and Rose Zacks for their comments on earlier versions of this paper. I would also like to thank Beth Chittenden, Sharron Francis, Zenzi Griffin, Dennis Larson, Dan Spieler, and Christy Stewart for their assistance in collecting the data. Correspondence should be addressed to G. A. Radvansky, Department of Psychology, University of Notre Dame, Notre Dame, IN 46556 (e-mail: radvansky.1@nd.edu). using memory probe (Lutz \& Radvansky, 1997; Suh \& Trabasso, 1993), recall (Trabasso \& van den Broek, 1985), and verbal protocol measures (Magliano \& Graesser, 1991; Suh \& Trabasso, 1993).

In the previous research, the target information was stored in a single situation model. For example, in studies of spatial distance effects, all of the objects in a common area would correspond to a single model, and the ease with which information was retrieved was influenced by the internal structure of that model. There were no cases in which information from several models was needed. For tasks that require information retrieval from across several models, the structure of individual models may not serve well to structure retrieval. This is because each model organizes only a small portion of the entire set. Another strategy, such as the use of a retrieval plan, is needed to ensure that all of the information is retrieved. The observed organization may thus reflect factors of such a retrieval strategy.

This idea that there is flexibility in how information in situation models is retrieved is supported by Taylor and Tversky (1997). In one experiment, they had subjects read stories about people doing activities in different locations. These stories were organized around either the people or the locations. Reading times were recorded. Afterward, subjects were given two memory tests; one probed whether two activities were done by the same person and the other probed whether two activities were done in the same location. The results showed that different measures favored different concepts. Reading time benefited more from a person-based organization, whereas memory accuracy and response times favored a location-based organization.

\section{Evaluation of Subjective Organization}

The present experiments explored memory for individual facts to assess subjective organization apart from an external organization, such as that provided by a story structure (e.g., Taylor \& Tversky, 1997). Although it is important to understand how people use such extrinsic 
structures, it is often the case that information must be organized subjectively. For example, when trying to reconstruct the circumstances of an automobile accident, there is often information from several witnesses that must be pieced together to provide an understanding of what happened.

The study sentences used here were either about objects in locations (e.g., "The pay phone is in the hotel") or about people in small locations (e.g., "The banker is in the telephone booth"), following other work on situation model retrieval (Radvansky, Spieler, \& Zacks, 1993; Radvansky \& Zacks, 1991; Radvansky, Zacks, \& Hasher, 1996). Although this task differs from most everyday comprehension situations, similar processes are likely to be operating. The object, person, and location concepts each had one to three associates. Cases in which multiple objects/people were associated with a single location are called single-location conditions, whereas cases where multiple locations were associated with a single object/ person are called multiple-location conditions. These facts could be organized in one of two obvious ways-the location concept or the object/person concept. The selection of an organization was determined entirely by the subject (there was no instruction to organize the facts). Because the sentences could be easily organized in only two ways, it was relatively straightforward to assess which way was being used. Each object or person could plausibly be found in any of the locations. Moreover, it was unlikely that people had any strong preexperimental associations among these concepts (Jones \& J. R. Anderson, 1987). Organization was primarily tested using recognition and recall.

Recognition. Recognition was used because only a single situation model needs to be compare with a memory probe. Mental organization was tested using a fan effect paradigm. A fan effect is an increase in response time accompanying an increase in the number of associations with a concept (J. R. Anderson, 1974). Fan effects occur when related information cannot be integrated in memory but not when it can (Moeser, 1979; Radvansky et al., 1993; Radvansky, Wyer, Curiel, \& Lutz, 1997; Radvansky \& Zacks, 1991; Radvansky et al., 1996; Radvansky, Zwaan, Federico, \& Franklin, in press; Smith, Adams, \& Schorr, 1978), as can be done with situation models. For example, it is difficult to integrate the facts "The potted palm is in the hotel" and "The potted palm is in the barber shop" because although they share a concept (potted palm), they refer to separate situations. Therefore, a separate model is constructed for each location. During retrieval, the appropriate situation model needs to be distinguished from those related to it. For example, when verifying "The potted palm is in the hotel," not only is the hotel model activated, but so is the barber shop model, because it also contains the concept potted palm. Consequently, the related and irrelevant model interferes with the retrieval of the appropriate one, thus increasing response time.

A fan effect does not occur when information can be integrated into a single situation model. It is relatively easy to integrate information about many objects in a single location, as in "The cola machine is in the airport" and "The welcome mat is in the airport" because it is plausible that these sentences refer to the same situation. So, during retrieval, there is little or no interference. Response time remains constant regardless of the number of items incorporated into the situation model.

This pattern of differential fan effects has been shown repeatedly. It occurs for both location- and person-based situations, with both definite or indefinite articles, and regardless of concept ordering in the study sentences (Radvansky et al., 1993; Radvansky et al., 1997; Radvansky \& Zacks, 1991; Radvansky et al., 1996; Radvansky et al., in press). Thus, the fan effect can be used to assess mental organization. Integrated representations do not show a fan effect, whereas separately stored and related representations do (Moeser, 1979; Smith et al., 1978).

Recall. Recall was also used because in this task an entire set of information must be reported that may be spread out across several situation models-for example, recalling all of the places visited during the day so that one can search for a lost letter. In order to retrieve this information successfully, some organization is needed. The demands of recall on the retrieval of information may show evidence of a retrieval plan rather than the situation models. A retrieval plan would help ensure that all of the items are recalled and that none are repeated. The organization of this retrieval plan may or may not correspond to the segregation of information into situation models. That is, the situation models may be structured on the basis of one principle, and the retrieval plan may be organized on the basis of another principle.

Organization was assessed on a recall test using output order (Thompson \& Roenker, 1971). The adjusted ratio of clustering (ARC) measure (Roenker, Thompson, \& Brown, 1971) was used to quantify recall organization. An ARC score is the proportion of possible categorical repetitions of items (contiguous recalls of items from the same category) adjusted for the chance probability of categorical repetitions. A score of 0 indicates chance clustering, whereas a score of 1 indicates perfect clustering. Subjects in the present study recalled the memorized facts several times because recall organizations stabilize after several trials (Tulving, 1962).

\section{EXPERIMENTS 1 AND 2}

Because Experiments 1 and 2 were so similar, they are presented together. In Experiment 1, the study facts were about objects in locations, such as "The pay phone is in the city hall." Previous studies with similar materials have revealed location-based organizations in recognition (Radvansky et al., 1993; Radvansky \& Zacks, 1991; Radvansky et al., 1996). In particular, a fan effect occurred for the multiple-location condition, but not the single-location condition. Experiment 2 used facts about people in small places that have revealed person-based organizations in recognition (Radvansky et al., 1993). The locations were 
small ones that typically contain only a single person at a time, such as a witness stand. A fan effect was observed for the single-location condition, but not for the multiplelocation condition. This person-based organization is the inverse of that observed with object-location materials. The reason for this is that it is unlikely that any of these locations would contain several people at one time. However, a person could go from place to place as part of a coherent sequence of events.

The difference between these observed organizations suggests that situation models are being used. For objects in locations, only situations in which several objects are in one place are plausible. In contrast, for people in small places, only situations in which a person travels from place to place are plausible. This distinction parallels Barwise and Perry's (1983) division of situations as states of affairs or courses of events. Of interest here is whether the demands of the recall test will show organizational patterns consistent with the recognition data.

\section{Method}

Subjects. Forty-eight native English speakers were tested in each experiment. An additional 3 subjects were replaced in Experiment $1-2$ for not accurately recalling the facts and 1 for equipment failure. An additional 6 subjects were replaced in Experiment 2-4 for not completing the experiment and 2 for not accurately recalling the facts. Testing was done individually in a single session lasting about $2 \mathrm{~h}$.

Materials and Procedure. Following Radvansky et al. (1993), people memorized a list of 18 facts using a study-test procedure. They were then given recognition and recall tests, the order of which was counterbalanced across subjects. Finally, subjects explicitly sorted the sentences.

For Experiment 1, the sentences were of the form "The object is in the location" or "The location has the object." Half of the people received facts in which the sentence subject was the object and half in which it was the location. Similarly, for Experiment 2, the sentences were of the form "The person is in/at the location" or "In/At the location is the person." Both concept orderings were included because although previous studies have produced similar results with both orders (e.g., Radvansky \& Zacks, 1991; Radvansky et al., 1996), those studies used only recognition, not recall. There is a tendency for forward associations to have a stronger influence than backward associations during recall (see, e.g., Wolford, 1971). Subjects were told to expect both recognition and recall memory tests.

Concepts were combined to form study sentences in a manner that resulted in conditions in which there were 1 to 3 associations for both concepts. The associative structure of a study list for a hypothetical subject in Experiment 1 is shown in Figure 1. For four sentences there was only one association for both concepts (e.g., "The bulletin board is in the public library"). Two of these sentences were arbitrarily assigned to the single-location condition, and the other two to the multiple-location condition. These items served as a baseline with which to compare higher fan levels. There were two sentences in each of the remaining object-location combinations. Items in which there was a single association with the object and multiple associations with the location composed the multiple-location condition, whereas those sentences in which there were multiple associations with the object and a single association with the location composed the single-location condition. A different random assignment of concepts to each condition was used for each subject. A similar list structure was used in Experiment 2. A listing of the concepts used in the experiments is given in the Appendix.

Subjects were told to memorize the items as efficiently as possible. Sentences were individually displayed in white on a black background for 7 sec each on a PC-compatible computer running in 40-column video mode. Sentences appeared half-way down the screen beginning on the left edge. A different random presentation order was used on each cycle After all of the study sentences had been presented, a set of test questions was given. In Experiment 1, the questions were of the form "Where is the object?" and "What is in the location?" In Experiment 2,
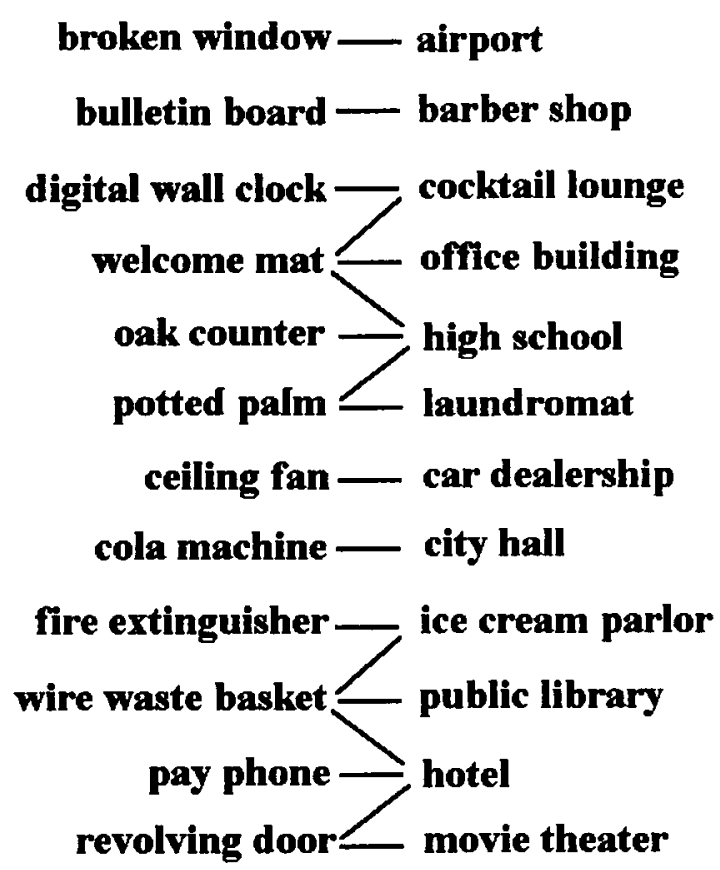

Figure 1. Schematic representation of the associations used to create the study lists.

they were of the form "Where is the person?" and "Who is in the location?" The test questions were randomly ordered on each cycle and an experimenter kept track of the responses. After answering all of the questions, the subject returned to the study portion. The criterion for memorization was the ability to correctly answer all of the test questions twice in a row. People required a mean of 4.8 cycles to memorize the facts in Experiment 1 and 4.7 cycles in Experiment 2.

The recognition test was timed and administered by computer. The left button of a computer mouse was used to indicate a studied fact, and the right button was used to indicate a nonstudied fact. Subjects were encouraged to respond as quickly and as accurately as possible. Nonstudied probes were created by re-pairing object/person and location concepts from within the same cell of the design. The order of probe presentation in the recognition test was randomized within each of eight blocks for a total of 288 trials. If a subject responded incorrectly, feedback was given for $1 \mathrm{sec}$ consisting of a line that read either "ERROR* SENTENCE STUDIED" or "*ERROR* SENTENCE NOT STUDIED," whichever was appropriate. A set of 18 practice trials was given to familiarize people with using the mouse buttons. On the practice trials the computer either displayed "SENTENCE STUDIED" or "SENTENCE NOT STLDIED," and the subject pressed the appropriate button. A self-timed break was allowed at the end of each quarter of the recognition test.

Only data from probe sentences where there was one association with one concept and one to three associations with the other were analyzed. Those sentences in which several objects were associated with several locations were not analyzed. Trials on which response times were shorter than $500 \mathrm{msec}$ or longer than $10 \mathrm{sec}$ were eliminated as anticipations and lapses of attention, respectively. Also, responses that were 2.5 SDs from a subject's mean in a given cell were eliminated as outliers. None of the trimmed data were counted as errors. This trimming eliminated $2.2 \%$ of the data in Experiment 1 and $3.0 \%$ in Experiment 2.

For the recall test, people orally recalled the memorized lists by reporting entire sentences while the experimenter kept track on a tally sheet. At the start of each trial, one of the study sentences was given. Subjects were asked to recall the study list as if the provided sentence were the first one that they themselves had recalled. This was done to prevent the use of a uniform recall order that could obscure the observation of subclusters. ${ }^{1}$ There were 18 recall trials for each subject, one with each study sentence as a starting sentence. The order of the starting sentences was randomized for each subject. Only trials in which all 
of the items were recalled were used. Any incomplete or incorrect recalis were repeated at the end of the recall test. A particular starting sentence was never repeated more than once.

The recall data were analyzed using the ARC score (Roenker et al., 1971). Different ARC scores were calculated for each organization type (i.e., $\mathrm{ARC}_{\text {object/person }}$ and $A R C_{\text {location }}$ ). An attractive feature in this study is that the $A R C_{\text {location }}$ and $A R C_{\text {object/person }}$ scores are independent. One score could be high and the other low, indicating a preference for one organization over another. Alternatively, both scores could be very low or very high, indicating a general lack of or propensity toward general organization, respectively.

After both memory tests, subjects did a card sorting task. They were given 18 index cards with a study sentence printed on each one. Subjects sorted the cards "based on what was written on them." They could make as many piles as they liked as long as there was more than one pile. ARC scores were calculated on the basis of these data.

\section{Results}

In Experiment 1, a location-based organization was observed in the recognition, recall, and sorting data. On the recognition test, a fan effect was present for the multiplelocation but not the single-location condition, suggesting a location-based organization. For recall, the locationbased organization was greater than the object-based organization. Finally, a greater location-based organization was also observed in the sorting task. In contrast, for Experiment 2, different organizations were observed in the recall and recognition data. A person-based organization was observed in recognition: A fan effect occurred for the single-location but not the multiple-location condition. However, a greater location-based organization was observed in recall. This organization was also observed in the sorting task. ${ }^{2}$ The absence of a consistent organization suggests that the organization of information retrieved from situation models is flexible.

Recognition. The response time data are summarized in Figure 2. The error rates were very low $(2.1 \%$ and $2.0 \%$

\section{Experiment 1}

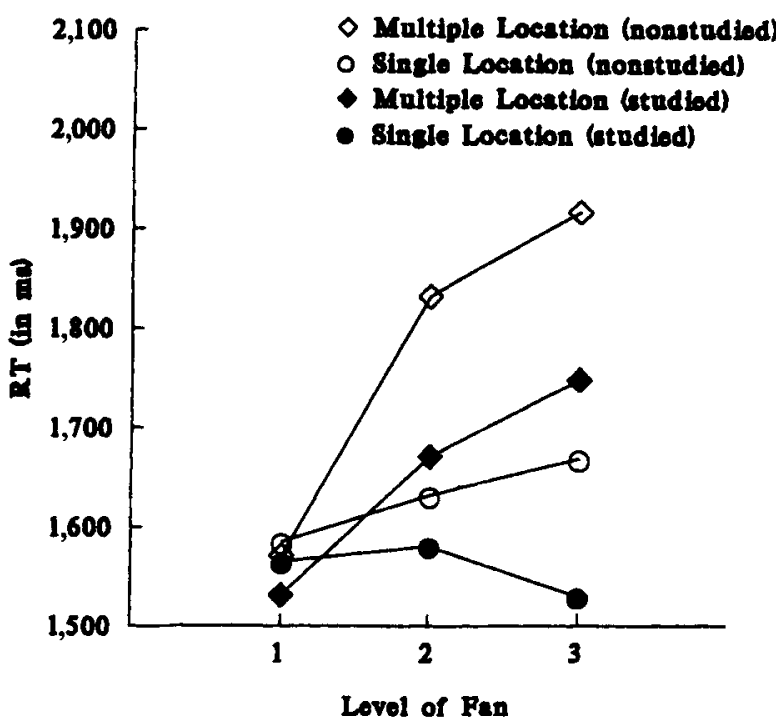

for Experiments 1 and 2, respectively), and so are not considered further. The response time data were submitted to a 2 (studied vs. nonstudied) $\times 2$ (condition: single location vs. multiple location) $\times 3$ (fan) repeated measures analysis of variance (ANOVA) ${ }^{3}$ Unless otherwise mentioned, statistical significance was set at $p<.05$. For Experiment 1, a location-based organization was observed. The condition $\times$ fan interaction was significant $\left[F(2,94)=6.00, M S_{\mathrm{e}}=73,870\right]$. Simple effects tests showed that the fan effect was significant for the multiplelocation condition $\left[F(2,94)=12.39, M S_{\mathrm{e}}=124,847\right]$, but not for the single-location condition $[F(2,94)=1.93$, $\left.M S_{\mathrm{e}}=61,283, p>.10\right]$. There was a main effect of condition, with subjects responding faster for single-location probes $(1,594 \mathrm{msec})$ than for multiple-location probes $(1,712 \mathrm{msec})\left[F(1,47)=26.07, M S_{\mathrm{e}}=107,814\right]$. There was also a significant main effect of fan [Fan Level $1=$ 1,$563 ; 2=1,679 ; 3=1,716 \mathrm{msec} ; F(2,94)=10.89$, $\left.M S_{\mathrm{e}}=112,260\right]$.

In contrast, for Experiment 2 a person-based organization was observed. The condition $\times$ fan interaction was significant $\left[F(2,94)=10.18, M S_{\mathrm{e}}=106,789\right]$. Simple effects test showed that the fan effect was significant for the single-location condition $\left[F(2,94)=15.55, M S_{\mathrm{e}}=\right.$ $150,443]$, but not for the multiple-location condition $(F<1)$. There was a significant main effect of condition, with people responding faster for multiple-location probes $(1,641 \mathrm{msec})$ than for single-location probes $[1,809 \mathrm{msec}$; $\left.F(1,47)=52.51, M S_{\mathrm{e}}=77,168\right]$. There was also a significant main effect of fan [Fan Level $1=1,643 ; 2=1,727$; $\left.3=1,805 \mathrm{msec} ; F(2,94)=10.54, M S_{\mathrm{e}}=119,129\right]$.

In addition to the effects of most interest, in both experiments people responded to studied probes faster $(1,604 \mathrm{msec} ; 1,699 \mathrm{msec})$ than to nonstudied probes

\section{Experiment 2}

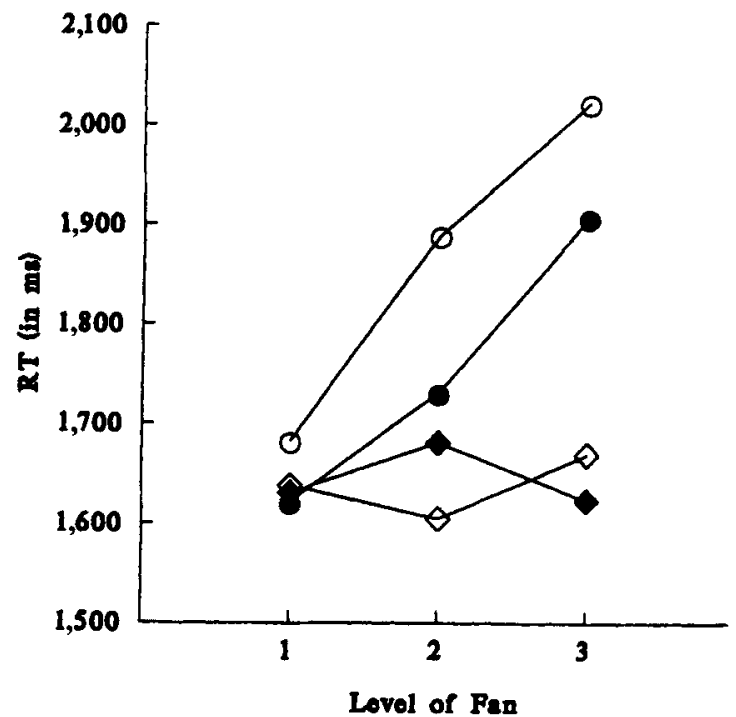

Figure 2. Response time results for Experiments 1 and 2. 
$\left[1,701 \mathrm{msec} ; 1,751 \mathrm{msec} ; F(1,47)=34.41, M S_{\mathrm{e}}=\right.$ 39,064 , and $\mathrm{F}(1,47)=5.49, M S_{\mathrm{e}}=69,853$, for Experiments 1 and 2, respectively]. Also, in both experiments, the difference between the single-location and multiplelocation conditions was greater for nonstudied probes (174 msec; $227 \mathrm{msec}$ ) than for studied probes (106 msec; $108 \mathrm{msec}$ ), as is evident by significant studied-nonstudied $\times$ condition interactions $\left[F(1,47)=5.48, M S_{\mathrm{e}}=29,666\right.$, and $F(1,47)=8.07, M S_{\mathrm{e}}=62,955$, for Experiments 1 and 2, respectively]. Simple effects tests in each experiment showed that the effect of condition was significant for both the studied $\left[F(1,47)=12.11, M S_{\mathrm{e}}=66,938\right.$, and $\left.F(1,47)=12.05, M S_{\mathrm{e}}=70,167\right]$ and nonstudied probes $\left[F(1,47)=30.65, M S_{\mathrm{e}}=70,542\right.$, and $F(1,47)=$ $\left.53.11, M S_{\mathrm{e}}=69,955\right]$.

Finally, in Experiment 1 the fan effect was larger for nonstudied probes (Fan Level $1=1,578 ; 2=1,732 ; 3=$ $1,793 \mathrm{msec}$ ) than for studied probes (Fan Level $1=1,548$; $2=1,626 ; 3=1,639 \mathrm{msec}$ ), as is evident by the significant studied-nonstudied $\times$ fan interaction $[F(2,94)=$ $\left.3.06, M S_{\mathrm{e}}=61,965, p=.05\right]$. A simple effects test showed that the fan effect was significant for the nonstudied probes $\left[F(2,94)=16.21, M S_{\mathrm{e}}=199,331\right]$, but only approached significance for the studied probes $\left[F(2,94)=2.28, M S_{\mathrm{e}}=\right.$ $101,375, p=.11]$. This reflects a general trend for fan effects to be greater in data from negative responses than from positive responses (J. R. Anderson, 1983).

Recall. Subjects had $0-8(M=2.7)$ recall trials repeated due to errors in Experiment 1 and $0-6(M=1.5)$ repeated in Experiment 2. In Experiment 1, the $\mathrm{ARC}_{\text {location }}$ scores were greater $(M=.85)$ than the $\mathrm{ARC}_{\text {object }}$ scores $\left[M=.44 ; F(1,47)=55.51, M S_{\mathrm{e}}=.075\right]$, suggesting greater location-based organization. There was a significant negative correlation between the $\mathrm{ARC}_{\text {location }}$ and $\mathrm{ARC}_{\text {object }}$ scores $(r=-.65)$, suggesting that greater preference for one organization accompanied less of a preference for the other. Similarly, for Experiment 2, a greater location-based organization was observed, with the $\mathrm{ARC}_{\text {location }}$ scores being greater $(M=.81)$ than the $\mathrm{ARC}_{\text {person }}$ scores $\left[M=.48 ; F(1,47)=18.42, M S_{\mathrm{e}}=.137\right]$. There was also a significant negative correlation between the $\mathrm{ARC}_{\text {location }}$ and $\mathrm{ARC}_{\text {person }}$ scores $(r=-.70)$.

Although the overall preferred organization was location based, there was a fair amount of both object-based and person-based organization (all ARC scores were significantly greater than zero). This reinforces the idea that there was variation in how this information was organized. In Experiment 1, 36 subjects had a preference for a location-based organization (the $\mathrm{ARC}_{\text {location }}$ score was .10 or more greater than the $\left.\mathrm{ARC}_{\text {object }} \mathrm{score}\right)\left(\mathrm{ARC}_{\text {location }}=\right.$ $\left..92 ; \mathrm{ARC}_{\text {object }}=.33\right), 7$ subjects had no organizational preference, but had highly organized recalls overall $\left(\mathrm{ARC}_{\text {location }}=.75 ; \mathrm{ARC}_{\text {object }}=.73\right)$, and the remaining 5 subjects had a greater preference for an object-based organization $\left(\mathrm{ARC}_{\text {location }}=.53 ; \mathrm{ARC}_{\text {object }}=.81\right)$. In Experiment 2, 28 subjects had a preference for a locationbased organization $\left(\mathrm{ARC}_{\text {location }}=.92 ; \mathrm{ARC}_{\text {person }}=.26\right.$ ), 12 people showed no preference, but had generally high organization overall $\left(\mathrm{ARC}_{\text {location }}=.74 ; \mathrm{ARC}_{\text {person }}=.75\right)$, and the remaining 8 subjects had a greater preference for a person-based organization $\left(\mathrm{ARC}_{\text {location }}=.49 ; \mathrm{ARC}_{\text {person }}\right.$ $=.87$ ). In both experiments, there was evidence of people switching from one organization to another during recall, a process called "pivoting" (Lancaster \& Barsalou, 1997).

Sorting. Two people in Experiment 1 were not given this task due to an experimenter oversight. The sorting data were analyzed like the recall data. ARC scores were calculated on the basis of whether a pair of items was placed in the same pile. Thus, if a pile contained three items from the same category, it was counted as two repetitions, even though the piles were not ordered. A greater location-based organization was consistently observed. The $\mathrm{ARC}_{\text {location }}$ scores were greater than the $\mathrm{ARC}_{\text {object/person }}$ scores for both Experiment $1[.94$ vs. . $28 ; F(1,45)=45.69$, $\left.M S_{\mathrm{e}}=.127\right]$ and Experiment $2[.78$ vs. $.55 ; F(1,47)=$ $\left.4.24, M S_{\mathrm{e}}=.302\right]$. The $\mathrm{ARC}_{\text {location }}$ and $\mathrm{ARC}_{\text {object/person }}$ scores were negatively correlated, significantly so for Experiment $2(r=-.44)$, but not for Experiment $1(r=-.11)$.

\section{DISCUSSION}

The present experiments tested whether a consistent organization is observed in different memory tasks for the retrieval of information stored in situation models. For Experiment 1, using object-location facts, a consistent organization was observed across tasks. However, it may be that only one organizational strategy was plausible. That is, the materials lent themselves to organization by location, not by object, because it is implausible for an object to travel from place to place. Therefore, it is conceivable that different processes generated the observed organizations in recall and recognition, but, because of the restrictive nature of the information, these organizations seemed consistent.

In contrast, in Experiment 2, using person small location facts, different organizations were observed. This is consistent with an experiment reported by Taylor and Tversky (1997) that also compared organization around person and location concepts in a narrative comprehension study. This could have occurred here because there were two plausible ways to organize the information. One can either imagine a person going from place to place, or a location in which people cycle through it. Which is used varies with respect to the demands of the task. As such, these materials are more open to organizational flexibility. Thus, the organization of information retrieved from situation models is flexible.

Such a flexibility in organization is seen in other domains of memory. For example, in research on autobiographical memory, it has been found that people can access information in a variety of ways ( $\mathrm{S}$. J. Anderson \& Conway, 1993; Barsalou, 1988; Lancaster \& Barsalou, 1997; Wagenaar, 1986). On some level, situation models and autobiographical memories are very similar in that they are both representations of events one of directly experienced events and one of vicariously experienced (via language) events. As such, some correspondence between autobiographical memories and situation models should be expected (Taylor \& Tversky, 1997).

The idea that recall and recognition have different influences in a fan effect paradigm was also shown by Whitlow, Smith, and Medin (1982) in a study in which subjects memorized facts about people performing activities, such as "The banker washed the wall." During learning, people repeatedly recalled the entire set of facts. Whitlow et al. found that although recalls tended to be clustered around both concept types, there was a greater preference for clustering around the activity concepts. Moreover, Whitlow et al. found no systematic relationship between the recall clustering and fan effect data. Some of the activities used (all of the materials were not provided) described actions that typically occur in a single location, such as "washed the wall" and "mowed the lawn." As such, it may be that these activities parallel the locations used in the present experiments and the recall data parallel the preference to organize by locations. However, since all the materials were not given, such conclusions are somewhat speculative. 
The present experiments showed that different organizations of the information stored in situation models may be observed for the same people in the same study. These different organizations were revealed here using recognition and recall. This flexibility is consistent with other research on situation models (see, e.g., Taylor \& Tversky, 1997) and on autobiographical memory (see, e.g., S. J. Anderson \& Conway, 1993).

\section{REFERENCES}

ANDERSON, J. R. (1974). Retrieval of propositional information from long-term memory. Cognitive Psychology, 6, 451-474.

ANDERSON, J. R. (1983). The architecture of cognition. Cambridge, MA: Harvard University Press.

ANDERSON, S. J., \& CoNWAY, M. A. (1993). Investigating the structure of autobiographical memories. Journal of Experimental Psychology: Learning, Memory, \& Cognition, 19, 1178-1196.

BARSALOU, L. W. (1988). The content and organization of autobiographical memories. In U. Neisser \& E. Winograd (Eds.), Remembering reconsidered: Ecological and traditional approaches to the study of memory (pp. 193-243). Cambridge, MA: Cambridge University Press.

Barwise, J., \& Perry, J. (1983). Situations and attitudes. Cambridge, MA: Harvard University Press.

GlenberG, A. M., MEYer, M., \& Lindem, K. (1987). Mental models contribute to foregrounding during text comprehension. Journal of Memory \& Language, 26, 69-83.

JOHNSON-LAIRD, P. N. (1983). Mental models: Towards a cognitive science of language, inference and consciousness. Cambridge, MA: Harvard University Press.

JoNes, W. P., \& ANDERSON, J. R. (1987). Short- and long-term memory retrieval: A comparison of the effects of information load and relatedness. Journal of Experimental Psychology: General, 116, 137-153.

LANCASTER, J. S., \& BARSALOU, L. W. (1997). Multiple organisations of events in memory. Memory, 5, 569-600.

LuTZ, M. F., \& RADVANSKY, G. A. (1997). The fate of completed goal information in narrative comprehension. Journal of Memory \& Language, 36, 293-310

Magliano, J. P., \& Graesser, A. C. (1991). A three-pronged method for studying inference generation in literary text. Poetics, 20, 193-232.

Moeser, S. D. (1979). The role of experimental design in investigations of the fan effect. Journal of Experimental Psychology: Human Learning \& Memory, 5, 125-134.

Morrow, D. G., Greenspan, S. L., \& Bower, G. H. (1987). Accessibility and situation models in narrative comprehension. Journal of Memory \& Language, 26, 165-187.

Radvansky, G. A., Spieler, D. H., \& ZaCks, R. T. (1993). Mental model organization. Journal of Experimental Psychology: Learning, Memory, \& Cognition, 19, 95-114.

Radvansky, G. A., Wyer, R. S., Curiel, J. M., \& Lutz, M. F. (1997). Situation models and abstract ownership relations. Journal of Experimental Psychology: Learning, Memory, \& Cognition, 23, 1233-1246.

Radvansky, G. A., \& ZaCKs, R. T. (1991). Mental models and fact retrieval. Journal of Experimental Psychology: Learning, Memory, \& Cognition, 17, 940-953

RADVANSKY, G. A., \& ZACKS, R. T. (1997). The retrieval of situationspecific information. In M. A. Conway (Ed.), Cognitive models of memory (pp. 173-213). Cambridge, MA: MIT Press.

Radvansky, G. A., ZACKs, R. T., \& HASHER, L. (1996). Fact retrieval in younger and older adults: The role of mental models. Psychology \& Aging, 11, 258-271
Radvansky, G. A., Zwaan, R. A., Federico, T., \& Franklin, N. (in press). Retrieval from temporally organized situation models. Journal of Experimental Psychology: Learning, Memory, \& Cognition.

Reitman, J. S., \& RueTER, H. H. (1980). Organization revealed by recall orders and confirmed by pauses. Cognitive Psychology, 12, 554-581.

RinCK, M., \& BowER, G. H. (1995). Anaphora resolution and the focus of attention in situation models. Journal of Memory \& Language, 34, $110-131$

Roenker, D. L., Thompson, C. P., \& Brown, S. C. (1971). Comparison of measures for the estimation of clustering in free recall. Psychological Bulletin, 76, 45-48.

Smith, E. E., AdAms, N., \& Schorr, D. (1978). Fact retrieval and the paradox of interference. Cognitive Psychology, 10, 438-464.

SuH, S. Y., \& Trabasso, T. (1993). Inferences during reading: Converging evidence from discourse analysis, talk-aloud protocols, and recognition priming. Journal of Memory \& Language, 32, 279-300.

TAYLOR, H. A., \& TVERSKY, B. (1997). Indexing events in memory: Evidence for index dominance. Memory, 5, 509-542.

Thompson, C. P., \& Roenker, D. L. (1971). Learning to cluster. Journal of Experimental Psychology, 91, 136-139.

Trabasso, T., \& VAN den Broek, P. W. (1985). Causal thinking and the representation of narrative events. Journal of Memory \& Language, 24, 612-630.

TulviNG, E. (1962). Subjective organization in free recall of "unrelated words." Psychological Review, 69, 344-354

VAN DiJK, T. A., \& KINTsCH, W. (1983). Strategies in discourse comprehension. New York: Academic Press.

WAGENAAR, W. A. (1986). My memory: A study of autobiographical memory over 6 years. Cognitive Psychology, 18, 225-252.

Whitlow, J. W., SMith, E. E., \& MEDIN, D. L. (1982). Retrieval of correlated predicates. Journal of Verbal Learning \& Verbal Behavior, 21, 383-402.

WOLFORD, G. (1971). Function of distinct associations for pairedassociate interference. Psychological Review, 78, 303-313.

ZWAAN, R. A., \& RADVANSKY, G. A. (1998). Situation models in language comprehension and memory. Psychological Bulletin, 123, 162-185.

\section{NOTES}

1. I had originally planned to use Reitman and Rueter's (1980) hierarchical organization algorithm, which can benefit from such a procedure. It was not used because the recalls were too variable and much information about even general organization was lost when it was used.

2. This difference among the recognition, recall, and sorting tasks was replicated in an additional pair of studies that used cued recall and the sorting task. For cued recall, an object, person, or location concept was presented and people had to recall all of the concepts associated with it (e.g., reporting all of the locations the banker was in). Time to respond was the dependent measure. As in Experiments 1 and 2, a location-based organization was always observed in the sorting data, but for cued recall a location-based organization was observed for the object-location facts, and a person-based organization was observed for the person/small location facts.

3. Initial analyses included order of memory test and sentence type as variables. However, these factors were not involved in any interactions, so the analyses are collapsed across them. 
APPENDIX

Subjects and Predicates Used in Experiments 1 and 2

\begin{tabular}{llll}
\hline \multicolumn{1}{c}{ Objects } & \multicolumn{1}{c}{ Locations } & People & \multicolumn{1}{c}{ Small Locations } \\
\hline Broken window & Airport & Architect & Old tire swing \\
Bulletin board & Barber shop & Banker & New car's driver's seat \\
Ceiling fan & Car dealership & Carpenter & Nearest voting booth \\
Cola machine & City hall & Doctor & Store's dressing room \\
Digital wall clock & Cocktail lounge & Engineer & Back room's tanning bed \\
Fire extinguisher & Ice cream parlor & Farmer & Greyhound bus's bathroom \\
Oak counter & High school & Grocer & Ornate throne \\
Pay phone & Grand hotel & Lawyer & Witness stand \\
Potted palm & Laundromat & Mechanic & Telephone booth \\
Revolving door & Movie theater & Salesman & Operating table \\
Welcome mat & Office building & Teacher & Blue and yellow kayak \\
Wire waste basket & Public library & Writer & Dark confessional \\
\hline
\end{tabular}

(Manuscript received April 30, 1997;

revision accepted for publication October $28,1997$. ) 